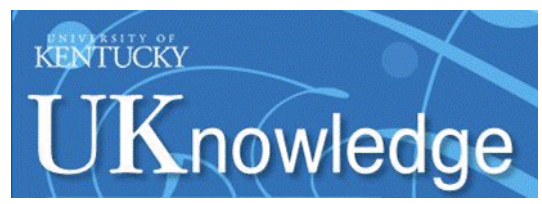

University of Kentucky

UKnowledge

\title{
Lung Metastasis Postradioembolization of Hepatocellular Carcinoma With Tumor in Vein
}

\author{
Harit Kapoor \\ University of Kentucky, haritkapoor@uky.edu \\ Sreeja Sanampudi \\ University of Kentucky, sreeja.sanampudi@uky.edu \\ Joseph W. Owen \\ University of Kentucky, joseph.owen@uky.edu \\ Driss Raissi \\ University of Kentucky, driss.raissi@uky.edu
}

Follow this and additional works at: https://uknowledge.uky.edu/radiology_facpub

Part of the Oncology Commons, and the Radiology Commons

Right click to open a feedback form in a new tab to let us know how this document benefits you.

\section{Repository Citation}

Kapoor, Harit; Sanampudi, Sreeja; Owen, Joseph W.; and Raissi, Driss, "Lung Metastasis

Postradioembolization of Hepatocellular Carcinoma With Tumor in Vein" (2020). Radiology Faculty

Publications. 25.

https://uknowledge.uky.edu/radiology_facpub/25

This Article is brought to you for free and open access by the Radiology at UKnowledge. It has been accepted for inclusion in Radiology Faculty Publications by an authorized administrator of UKnowledge. For more information, please contact UKnowledge@lsv.uky.edu. 


\section{Lung Metastasis Postradioembolization of Hepatocellular Carcinoma With Tumor in Vein}

\section{Digital Object Identifier (DOI)}

https://doi.org/10.14309/crj.0000000000000322

\section{Notes/Citation Information}

Published in ACG Case Reports Journal, v. 7, issue 2, e00322, p. 1-4.

\section{(C) 2020 The Author(s).}

This is an open-access article distributed under the terms of the Creative Commons Attribution-Non Commercial-No Derivatives License 4.0 (CCBY-NC-ND), where it is permissible to download and share the work provided it is properly cited. The work cannot be changed in any way or used commercially without permission from the journal. 


\title{
CASE REPORT | LIVER
}

\section{Lung Metastasis Postradioembolization of Hepatocellular Carcinoma With Tumor in Vein}

\author{
Harit Kapoor, MBBS ${ }^{1}$, Sreeja Sanampudi, $\mathrm{MD}^{1}$, Joseph Owen, $\mathrm{MD}^{1}$, and Driss Raissi, MD ${ }^{1}$ \\ ${ }^{1}$ Department of Radiology, University of Kentucky Chandler Medical Center, Lexington, KY
}

\begin{abstract}
Transarterial radioembolization (TARE) is one of the few treatment options available for infiltrative hepatocellular carcinoma with tumor in vein. This is backed by the published data showing marginally favorable toxicity profile compared with other locoregional and systemic therapies. Although lung shunt fraction studies are performed to prevent radiation injury to the lungs, TARE-induced embolization/metastasis to the lungs has not been reported before. We report an intriguing case of new lung metastases within 1 month after TARE for infiltrative hepatocellular carcinoma with a tumor in the vein, with only a slightly elevated but acceptable lung shunt fraction. This report brings to light the possibility of such a complication and argues for improved preprocedural assessment of a tumor in vein burden and embolization potential.
\end{abstract}

\section{INTRODUCTION}

Infiltrative hepatocellular carcinoma (IHCC) is a subtype of advanced HCC that carries a very poor prognosis, especially when associated with tumor in vein (TIV). In these patients, treatment options are limited. ${ }^{1}$ Locoregional therapies such as transarterial radioembolization (TARE) with or without chemotherapy are performed in the liver-limited disease to downstage. TARE delivers hepatic-selective brachytherapy, relying on the preferential arterial perfusion of the tumor. TARE has been shown to offer some survival benefit but more importantly a milder toxicity profile compared with other therapies for IHCC-TIV., ${ }^{2,3}$ We present an intriguing case of new lung metastases within 1 month after radioembolization of an IHCC-TIV.

\section{CASE REPORT}

A 56-year-old man with hepatitis C-related cirrhosis presented with new right upper abdominal pain. Other comorbidities included hypertension, coronary artery disease status post bypass grafting, and epilepsy. He denied gastroenterology follow-up after the diagnosis of cirrhosis 5 years ago. History of present illness revealed unintentional weight loss of 50 pounds and dark colored urine worsening over the past year. Mild icterus and right upper quadrant tenderness were elicited on physical examination. Laboratory workup revealed an hemoglobin of $13.5 \mathrm{~g} / \mathrm{dL}$, platelets of $205 \mathrm{k} / \mathrm{uL}$, creatinine of $0.6 \mathrm{mg} / \mathrm{dL}$, aspartate aminotransferase of $198 \mathrm{U} / \mathrm{L}$, alanine aminotransferase of $41 \mathrm{U} / \mathrm{L}$, alkaline phosphatase level of $119 \mathrm{IU} / \mathrm{L}$, international normalized ratio of 1.2, serum sodium of $127 \mathrm{mmol} / \mathrm{L}$, bilirubin of $2.1 \mathrm{mg} / \mathrm{dL}$, and alpha-feto-protein (AFP) level of 354,260 ng/mL. Specific disease scores were calculated to be Child-Pugh Class B and Model for End-Stage Liver Disease-Sodium of 21. Imaging showed an infiltrative necrotic $12 \times 10-\mathrm{cm}$ mass within posterior segments of the right liver (VI and VIII) along with the thrombosis of the right posterior portal vein, reported as Liver Imaging Reporting and Data System-TIV (Figure 1). A complete diagnosis of unresectable Stage IV-B (T3bN1M0) hepatocellular carcinoma was made after tumor board review. Interventional radiology was consulted for TARE. Review of preprocedural imaging revealed unremarkable arterial anatomy. Three weeks later, the patient underwent arterial mapping with Technetium-99m macroaggregated albumin (Tc-99m MAA; $4.15 \mathrm{mCi}$ ) via standard right femoral artery access and right hepatic superselection. Postmapping liver imaging with single-photon emission computed tomography (SPECT-CT) revealed the expected tracer distribution and an acceptable but borderline high-lung shunt fraction (LSF) of 11\% (Figure 2). After another 5-week interval, 133.5mCi dose of Y-90 TheraSphere (MDS Nordion, Ottawa, ON, Canada) was administered to targeted segments. 


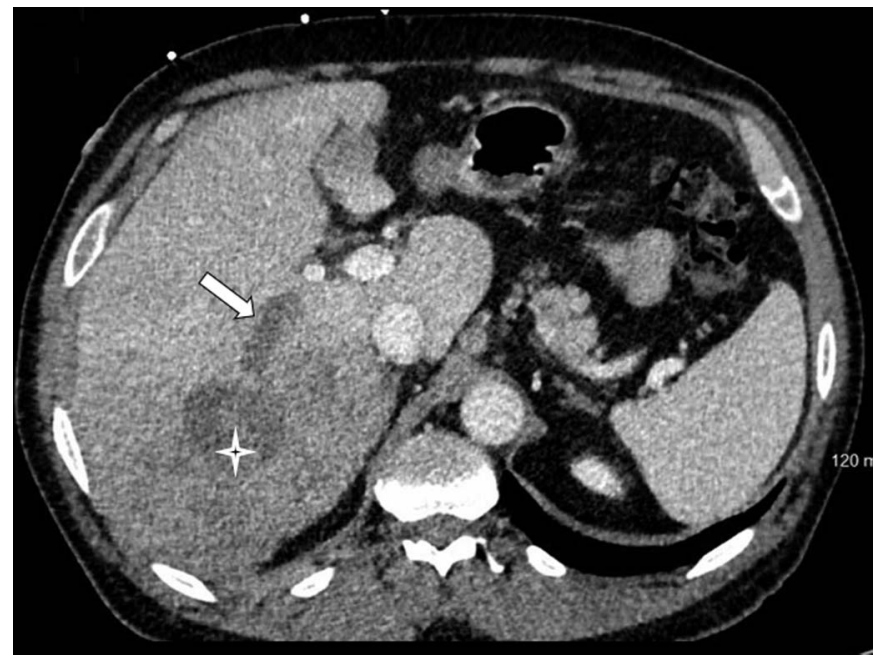

Figure 1. Axial contrast-enhanced computed tomography images before transarterial radioembolization showing a necrotic mass (white star) and tumor in the vein within the right posterior portal vein branch (white arrow).

Tracer localization was limited to tumor-containing hepatic segments on postprocedure bremsstrahlung SPECT-CT. Unfortunately, the patient presented back to the emergency department 3 weeks post-TARE with severe abdominal pain. Abdominal, thoracic, and pelvic contrast-enhanced CT demonstrated necrosis within the index tumor (Figure 3) but with new findings of multiple lung metastases which were not present on the thoracic CT performed 53 days before Y-90 embolization (Figure 4). Laboratory test results revealed only a modest drop in AFP. Prominent arterioportal shunting was evident on a retrospective review of intraprocedural images (Figure 5). The patient did not tolerate sorafenib therapy and ultimately opted for home hospice.

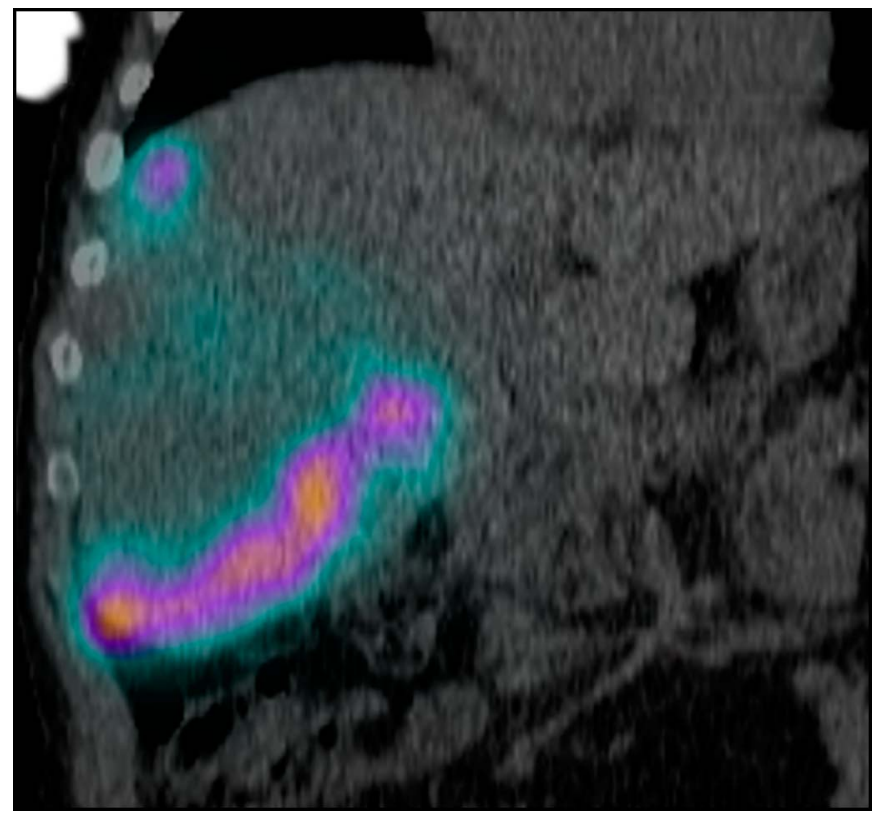

Figure 2. Single-photon emission computed tomography imaging after initial arterial mapping procedure.

\section{DISCUSSION}

We present a case of metastatic disease to the lungs within one month after radioembolization of an infiltrative HCC with branch portal vein thrombus. A significant limitation to this report is the possibility of metastatic progression in the near 2month gap period between preoperative imaging and embolization, especially considering the aggressive tumor profile. However, it would be irrational to dismiss the alternative possibility of iatrogenic metastatic facilitation.

Embolization with beta-emitter Y-90 is indicated in unresectable HCC when (i) HCC is liver limited, (ii) expected survival of at least 12 weeks with the Eastern Cooperative Oncology Group (ECOG) performance status of $<2$, and (iii) acceptable hepatic functional status (lack of ascites, total bilirubin $<2 \mathrm{mg} / \mathrm{dL}$, and albumin $>3 \mathrm{mg} / \mathrm{dL}$ ). ${ }^{4}$ Absolute contraindications to the procedure include a LSF $>20 \%$ or a predicted single session lung dose estimation of $>30 \mathrm{~Gy}$ on postmapping SPECT. ${ }^{4}$ Complications include procedurerelated vascular injury, postembolization syndrome, and most importantly complications arising from nontarget embolization.

Radiation pneumonitis can be a serious complication with hepatopulmonary shunting being quite common in patients with cirrhosis. In fact, patients who develop HCC and especially those with IHCC-TIV are more strongly associated with such shunting. ${ }^{5}$ This very disease attribute makes it mandatory to perform preprocedure mapping to estimate LSF. In addition to being a good predictor for complications such as radiation pneumonitis, LSF has also been shown to be an independent predictor of metastatic risk in HCC, with 2 times higher LSFs in those with extrahepatic metastases. ${ }^{6}$ LSF is currently

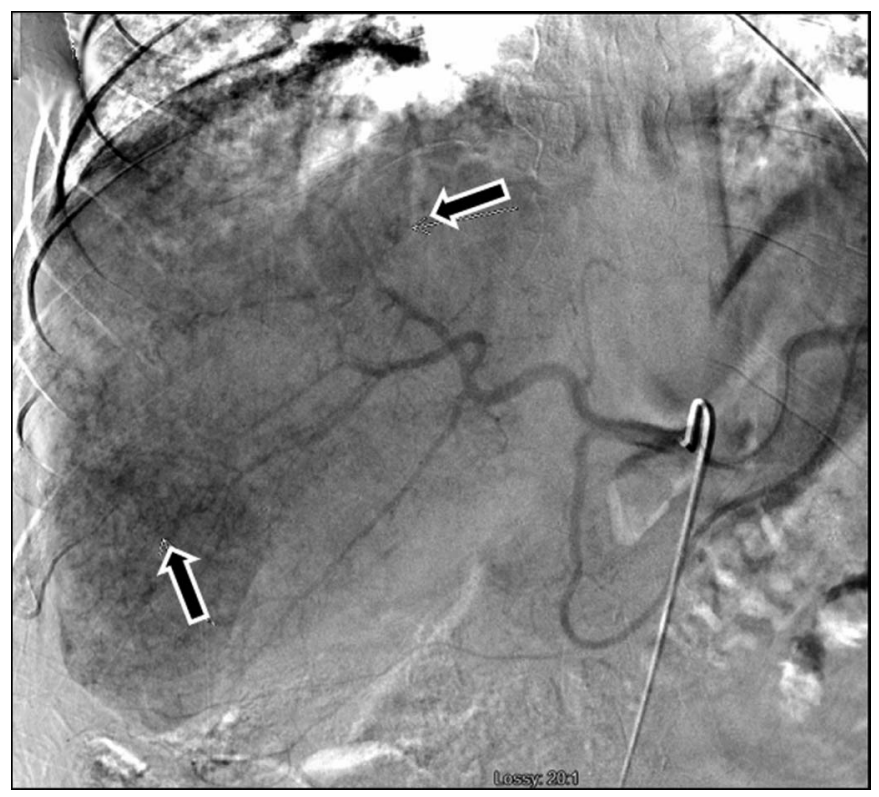

Figure 3. Retrospective review of intraprocedural digital subtraction angiographic acquisition showing prominent arterioportal shunting. 


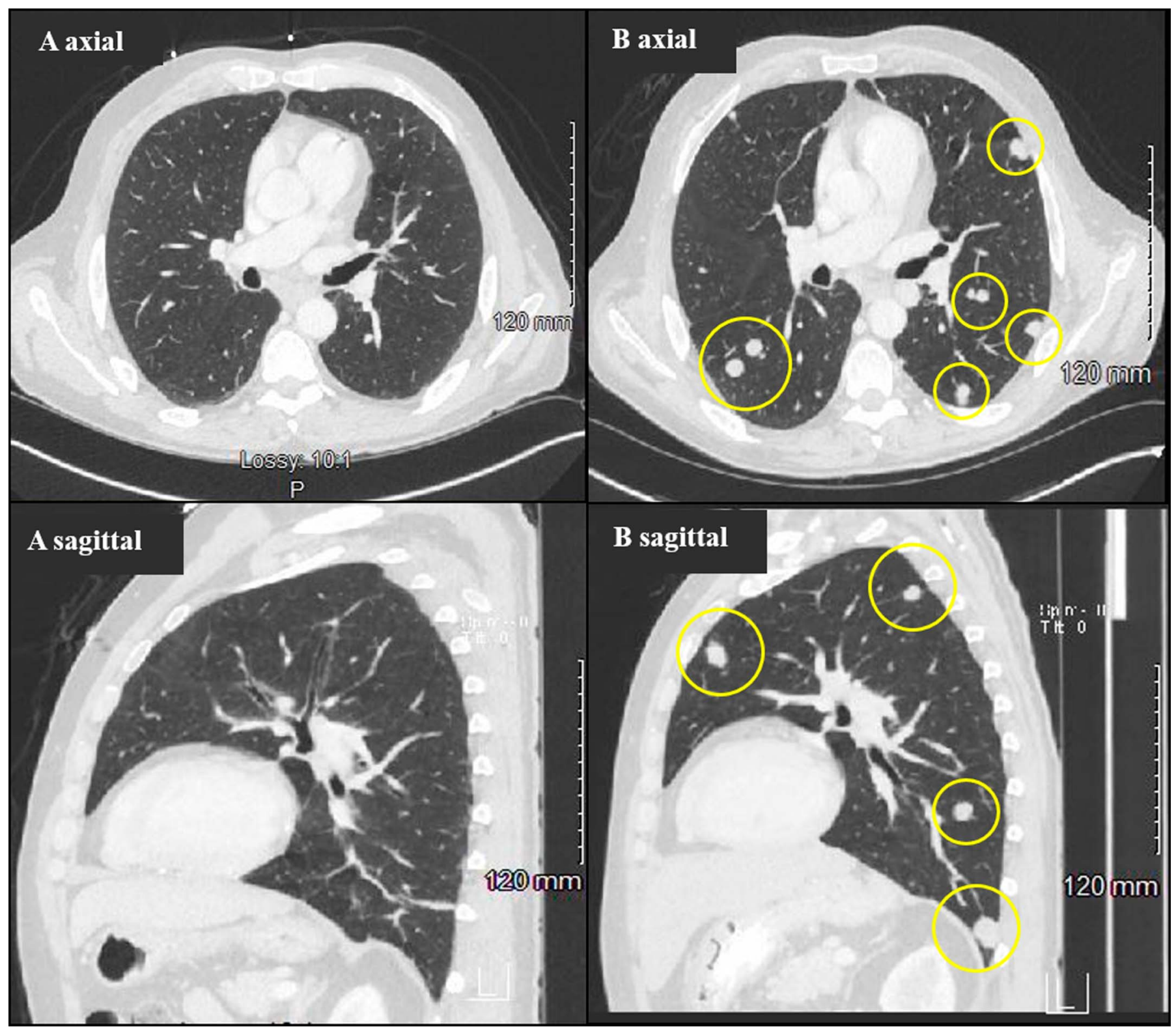

Figure 4. Representative lung window computed tomography images at comparable axial and sagittal planes, (A) before and (B) after transarterial radioembolization showing the development of new multifocal rounded pulmonary metastasis (yellow circles).

performed by injecting Tc-99m MAA intra-arterially into the liver as a test run before actual Y-90 administration. In most centers, images are then obtained using a planar gamma camera. The fraction of total counts reaching the lung (LSF) are derived by calculating the geometric mean of counts detected in the manually drawn region of interest over the lung on both anterior and posterior planar views. LSF values are known to become less reliable with time, especially beyond 4 hours because of biologic disintegration of MAA. ${ }^{7}$ LSF was calculated with planar imaging at 45 minutes postinjection in our case. Although SPECT-CT is performed at many centers, for visual assessment of extrahepatic deposition, it is not routinely used for LSF calculation. Given its poor anatomic resolution and the inability of performing attenuation correction, planar imaging is prone to overestimation of shunt fraction when compared with SPECT-CT. ${ }^{8}$ Ideally, LSF should be less than $10 \%$. Although dose adjustments can be performed in patients with LSF ranging between $10 \%$ and $20 \%$, those with LSF exceeding $20 \%$ are excluded from treatment. ${ }^{9}$ Although our patient only had a borderline high LSF of $11 \%$, multiple other risk factors for metastatic progression were present including a large tumor burden with macrovascular invasion and very high AFP levels. To this point, Fleming et al proposed a judicious way of pre-TARE patient selection by inversely customizing the LSF cutoff based on anatomic tumor bulk and aggressive features. ${ }^{5}$

An abscopal effect of radiation-induced augmentation of antitumor immune response has been described in the literature. ${ }^{10}$ On the contrary, this case exhibits a "reverse" abscopal effect. 


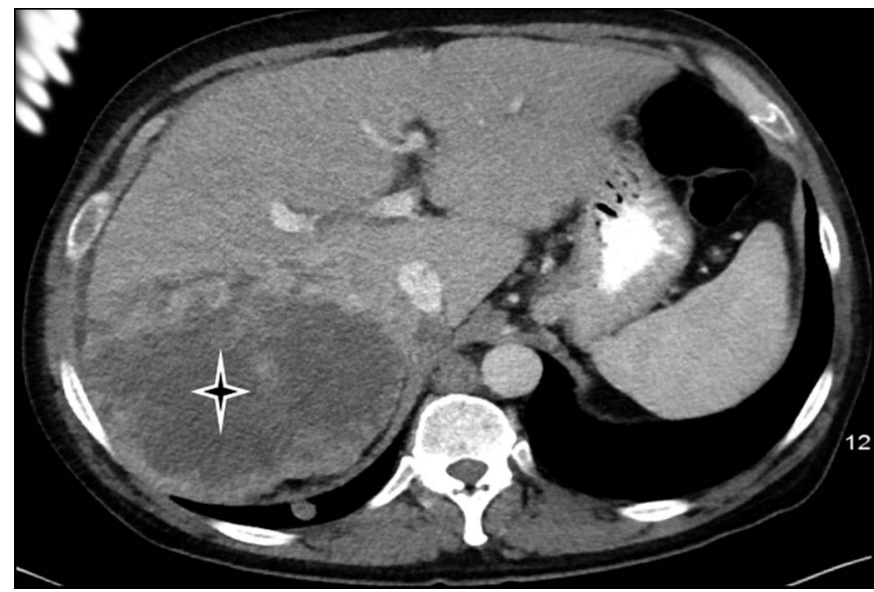

Figure 5. Axial contrast-enhanced computed tomography images taken 53 days after transarterial radioembolization showing the necrosis of the index tumor (black star).

Our literature search for similar cases incidentally revealed a growing body of evidence showing a trend for regional (but not metastatic) tumor potentiation after other locoregional therapies including ablation and transarterial chemoembolization. ${ }^{11-13}$ Tumor size, proximity to a sizeable portal vein, infiltrative morphology, and lower age have been linked to higher risk of such an occurrence. ${ }^{11}$ Multiple potential mechanisms have been proposed: (i) iatrogenic arterioportal shunt creation, (ii) induction of immune activation (high regional hepatocyte growth factor which in turn can activate downstream c-Met pathway leading to a greater vascular endothelial growth factor synthesis) and, (iii) increased intratumor pressure from associated edema causing rupture of the index lesion and dissemination of viable tumor cells. ${ }^{11,12,14}$ In conclusion, this report brings to light the possibility of metastatic potentiation after TARE in patients with IHCC-TIV and argues for improved preprocedural assessment of TIV burden and thoughtful consideration of adjunctive biochemical markers, especially when deciding for TARE candidacy in patients with borderline elevated LSF values.

\section{DISCLOSURES}

Author contributions: H. Kapoor and S. Sanampudi wrote the manuscript. J. Owen and D. Raissi revised the manuscript. $\mathrm{H}$. Kapoor is the article guarantor.
Financial disclosure: None to report.

Informed consent was obtained for this case report.

Received July 7, 2019; Accepted December 19, 2019

\section{REFERENCES}

1. Heimbach JK, Kulik LM, Finn RS, et al. AASLD guidelines for the treatment of hepatocellular carcinoma. Hepatology. 2018;67(1):358-80.

2. Riaz A, Lewandowski R, Salem R. Radioembolization in advanced hepatocellular carcinoma. J Clin Oncol. 2018;36(19):1898-901.

3. Abouchaleh N, Gabr A, Ali R, et al. Y radioembolization for locally advanced hepatocellular carcinoma with portal vein thrombosis: Long-term outcomes in a 185-patient cohort. J Nucl Med. 2018;59(7):1042-8.

4. Coldwell D, Sangro B, Wasan H, Salem R, Kennedy A. General selection criteria for patients for radioembolization of liver tumors: An international working group report. Am J Clin Oncol. 2011;34:337-41.

5. Fleming CJ, Andrews JC, Wiseman GA, Gansen DN, Roberts LR. Hepatic vein tumor thrombus as a risk factor for excessive pulmonary deposition of microspheres during TheraSphere therapy for unresectable hepatocellular carcinoma. J Vasc Interv Radiol. 2009;20(11):1460-3.

6. Sandow T, Devun D, Gulotta P, Bohorquez H, Kirsch D. Elevated lung shunt fraction as a prognostic indicator for disease progression and metastasis in hepatocellular carcinoma. J Vasc Interv Radiol. 2016;27(6):804-11.

7. De gersem R, Maleux $\mathrm{G}$, Vanbilloen $\mathrm{H}$, et al. Influence of time delay on the estimated lung shunt fraction on $99 \mathrm{mTc}$-labeled MAA scintigraphy for $90 \mathrm{Y}$ microsphere treatment planning. Clin Nucl Med. 2013;38(12):940-2.

8. Dittmann H, Kopp D, Kupferschlaeger J, et al. A prospective study of quantitative SPECT/CT for evaluation of lung shunt fraction before SIRT of liver tumors. J Nucl Med. 2018;59(9):1366-72.

9. Kallini JR, Gabr A, Salem R, Lewandowski RJ. Transarterial radioembolization with yttrium-90 for the treatment of hepatocellular carcinoma. Adv Ther. 2016;33:699-714.

10. Waxweiler TV, Raben D. "Chapter 5-Biologics and their interactions with radiation.” In: Gunderson LL, Tepper JE. Clinical Radiation Oncology, 4th edn. Elsevier: Philadelphia, PA, 2016, pp 80-92.e4.

11. Kang TW, Lim HK, Cha DI. Aggressive tumor recurrence after radiofrequency ablation for hepatocellular carcinoma. Clin Mol Hepatol. 2017;23(1):95-101.

12. Ahmed M, Kumar G, Moussa M, et al. Hepatic radiofrequency ablationinduced stimulation of distant tumor growth is suppressed by c-Met inhibition. Radiology. 2016;279(1):103-17.

13. Song KD, Lee MW, Rhim H, et al. Aggressive intrasegmental recurrence of hepatocellular carcinoma after combined transarterial chemoembolization and radiofrequency ablation. Am J Roentgenol. 2016;207(5):1122-7.

14. Kotoh K, Nakamuta M, Morizono S, et al. A multi-step, incremental expansion method for radio frequency ablation: Optimization of the procedure to prevent increases in intra-tumor pressure and to reduce the ablation time. Liver Int. 2005;25:542-7.

Copyright: ( 2020 The Author(s). Published by Wolters Kluwer Health, Inc. on behalf of The American College of Gastroenterology. This is an open-access article distributed under the terms of the Creative Commons Attribution-Non Commercial-No Derivatives License 4.0 (CCBY-NC-ND), where it is permissible to download and share the work provided it is properly cited. The work cannot be changed in any way or used commercially without permission from the journal. 